\title{
Strategies to Improve the Cost Effectiveness of Broiler Production
}

\author{
S.M.R. Samarakoon ${ }^{*}$ and K. Samarasinghe ${ }^{1}$ \\ Postgraduate institute of Agriculture \\ University of Peradeniya
}

Sri Lanka

\begin{abstract}
This study was done using 2550 day-old, sex separated chicks (1275 males \& 1275 females) to determine the most profitable grow-out period for broilers using different cost related performance indices and to ascertain the cost-effectiveness of sex-separate feeding of broilers. Feed intake and body weight were measured weekly for both sexes separately. Mortality, if any, during the rearing period was recorded. Average weight gain and Feed Conversion Ratio (FCR) of birds were calculated on a weekly basis up to the age of 35 day. Records of the same parameters were taken daily from day 36 to 42. Cost-benefit analysis was done using FCR, Performance Efficiency Factor (PEF), Unit Profitability (UP) and Unit Return Index (URI). FCR increased with increasing age in both sexes from day 1 to 42. Males had a significantly higher $(P<0.05)$ PEF from day 36 to 42 than females. Males had the highest PEF on day 36 and females on day 35. UP and URI values were significantly higher $(P<0.05)$ in males than in females from day 35 to 42 . Males had the highest UP and URI at day 40. In female broilers, UP and URI continued to increase up to day 42. The days giving highest values for PEF, UP and URI can be considered as optimum grow-out period for both males and females. Further studies are needed to determine the highest UP and URI values in females.
\end{abstract}

Keywords: Broiler, feed conversion ratio, performance efficiency factor, sex-separate, unit profitability

\section{INTRODUCTION}

The genetic potential for growth of the modern broiler chickens is continuously improving by $50 \mathrm{~g}$ each year. Therefore, the marketing age of broilers decreases yearly by an average of 0.75 day (Gunasekar, 2007). As a result of this genetic improvement, today's broiler is gaining an average of $50 \mathrm{~g}$ per day under conditions existing in developed countries, but it is estimated that the same broiler has the potential to double this performance (Creswell, 2007). The standard in broiler performance is achievement of $2.5 \mathrm{~kg}$ live weight with a feed conversion ratio of 1.72 at 42 day of age in recent times (Creswell, 2005).

The Sri Lankan broiler industry today is in the hands of the private sector. Contract grower or buy-back system is well established. The marketing age of broilers is decided by the buyback operator and it is in favor of the marketable dressed bird size. Dressed whole chicken represents more than $60 \%$ of the chicken sale in the Sri Lankan market and consumer preference is for weight range between 1 and $1.2 \mathrm{~kg}$. Therefore, the buy-back operators tend to catch the birds before 42 day. Large companies with environmentally controlled-houses

* Department of Animal Science, Faculty of Agriculture, University of Peradeniya, Peradeniya, Sri Lanka

Author for correspondence: rohitha@cicfeeds.lk 
place more broilers per house than recommended capacity. Hence, they start catching birds at day 32-33 by giving the first preference to big birds. In both cases the producer may lose the fast growing period of bird's life and at the same time they feed extra days for slow growing birds, especially the females.

Rapid escalation of raw-material prices in the world market causes increase in animal feed prices. Tax imposed by the Sri Lankan government on imported raw materials influenced furthermore on local feed price. The price of broiler chicken is being increased with time, though slowly and not simultaneously with the feed prices. However, further increase in chicken price has been brought to an end by the maximum retail price being set for whole chicken by the Consumer Affairs Authority of Sri Lanka.

It is clear that there are no hard and fast rules for maximizing the return from broiler production. Maximum profit could be achieved by getting a highest margin over the variable cost. There are two ways to increase the margin. Firstly, returns needs to be increased, either through achieving higher levels of production or through selling the product at a higher price. Secondly, the variable cost should be reduced as much as possible. According to Waller (2007), feed cost is the primary component of the variable cost, accounting for up to $70 \%$ of the total cost. When faced with increases in feed ingredient prices, only way to cut down the feed cost would be by reducing the nutrient specifications of the feed (Waller, 2007). Decreasing nutrient levels reduces feed cost but can also decrease the margin. Therefore, desire to reduce feed cost per ton wants to be balanced against maintaining or maximizing the margin. The maximum margin is clearly not produced by minimizing feed cost, but is achieved at the point where the difference between revenue and cost is maximum (Waller, 2007).

Increase in technical efficiency and use of new strategies at the farm are two important components in maximizing the margin. Sex-separate feeding and maintaining optimum grow-out period of birds are two strategies that farmers can easily apply to increase the profitability of the farm. The sexual difference of the birds has made a big difference in physiological requirements and also nutrient requirements. For example, the FCR of female broilers is usually higher (less efficient) than that of male birds of the same age, above 30 days or so as the female birds tend to deposit proportionally more fat in the body (Leeson, 2000). Veerapen (1999) showed that Ross 208 male broilers require less feed to produce a unit of gain in weight, and are more efficient feed converters than females and also male broilers could be slaughtered 4.5 day earlier than females, saving on feed costs, when raised separately. The males can be kept for more days after achievement of target slaughter live weight to achieve a heavier carcass weight and high meat yield for value added broiler choice cuts and the smaller females can be kept to meet the whole carcass market (Veerapen, 1999). The nutrient requirements of males and females are different due to the faster growth and higher meat yield of males and there is a possibility of feeding lower levels of protein or amino acids to the females (Creswell, 2007).

The cycle length is also an important factor when the annual return from the broiler business is considered. Extending cycle length will increase the return per bird, whereas, shortening the grow-out time will increase the number of harvests per year. Kleyn (2002) pointed out that a 38-day cycle length with an 11-day cleanout would lead to an extra harvest per year compared to the traditional practice of 42-day cycles with 14-day intervals.

The main focus of the poultry industry used to be on growth rate and feed conversion efficiency during the past. But with the current changes, now and increasingly in the future, 
this must be biological performance as well as economic parameters which are important to evaluate the real broiler performance. There are a few performance indices available to measure the performance of broilers. Most of them depict only the biological performance of the birds; they can be used to measure genetic potential of the bird, feed quality and technical efficiency of the farm.

Over the time industry has moved from a simple measure of bird weight, to weight for age, mortality, FCR, and more recently production efficiency factor (PEF) and unit profitability (UP). Together with growth rate, days to market and mortality, feed efficiency has been considered as one of the important parameters in assessing the potential of bird strain or feeding program etc (Leeson, 2000).

The ultimate profit of the operation is the most important circumstance to any commercial activity. Hence measurement of cost driven factors or performance in terms of returns rather than cost is more useful in terms of profitability of the business. Therefore, the objective of this study was to determine the most profitable grow-out time for broilers using different cost related performance indices and to ascertain the cost-effectiveness of sex-separate feeding of broilers.

\section{MATERIALS AND METHODS}

Two thousand five hundred and fifty (1275 males and 1275 females), day-old broiler chicks (Hubbard Flex) were used in total for the feeding trials. Day old chicks were obtained in 25 batches of 102 birds (51 males +51 females) in 2 weeks intervals. They were housed for brooding in two separate pens. The brooder was prepared 24 hours before placing the birds. The floor space at the brooder was $0.25 \mathrm{ft}^{2}$ per chick. Paddy husk was used as the bedding materials in brooder. Electric bulbs were used as heating source at 1 watt per chick. Chick trays were used for feeding chicks. Following one week of brooding, the same pens were used to keep birds during grow out period. The floor space per bird given from day 8 up to day 28 was $0.75 \mathrm{ft}^{2}$ and day 29 up to day 42 was $1.0 \mathrm{ft}^{2}$. Deep litter system was practiced and paddy husk was used as the litter material. Each pen was equipped with two round feeders (7 kg capacity) and two manual drinkers (9L capacity). A two-phase feeding program was adopted, where the broilers were fed on broiler starter crumbles from day 1 to day 21 and broiler finisher pellets from day 22 up to day 42. Ad lib feeding was done through out the period.

The birds were given infectious bursal disease vaccine (Bur 706) on day 7 and day 14 . Supplement of vitamins and other management practices were continued as usual but common to all birds. In the evening of the $42^{\text {nd }}$ day all birds were removed from the farm for slaughtering. After the birds were removed from the pen for slaughtering, all the litter materials were removed and pens were washed with clean water and followed by spraying a broad spectrum disinfectant. After that lime was applied on the floor area and the pen was kept free of chicks for next three weeks. Each production cycle (51 males +51 females) was considered as one replicate in two treatments. This practice was continued until 25 batches (50 groups) in total were considered as 25 replicates. Therefore, the total in vivo experimental period was 60 weeks.

Group feed intake and body weight were measured every week for both sexes separately. Mortality, if any, during the rearing period was recorded. Average weight gain and FCR of birds were calculated on weekly basis up to the age of 35 days. The same parameters were 
taken daily from 36 to $42^{\text {nd }}$ day for every batch. Cost-benefit analysis was done using the parameters such as FCR, PEF, UP and the unit return index (URI) in order to find out the most profitable age of broilers under different scenarios and to ascertain the costeffectiveness of sex-separate feeding. The following formulae were used to calculate the above parameters.

$$
\begin{aligned}
& F C R=\frac{\text { Feedintake }}{\text { Weightgain }} \\
& \text { PEF }=\frac{\text { Liveweight }(\text { kg }) \times \text { Livability }(6)}{\text { Ageatdepletion }(\text { days }) \times F C R} \times 100 \\
& U P=\frac{[(\text { Incomefrombirds } / m 2)-(\text { Allcosts } / m 2)]}{\text { Cyclelength }(\text { days })}
\end{aligned}
$$

$U R I=[(A \times B \times C \times D)-(E \times F \times A)-(G)-(H)] /$ Age in days

$$
\begin{array}{ll}
\mathrm{A}=\text { Average body weight }(\mathrm{kg}) & \mathrm{E}=\text { Average feed cost }(\mathrm{Rs} / \mathrm{kg}) \\
\mathrm{B}=\text { Stocking rate }\left(\mathrm{kg} / \mathrm{m}^{2}\right) & \mathrm{F}=\mathrm{FCR} \\
\mathrm{C}=\text { Livability }(\%) & \mathrm{G}=\text { Medication cost per bird }(\mathrm{Rs}) \\
\mathrm{D}=\text { Live weight price }(\mathrm{Rs} / \mathrm{kg}) & \mathrm{H}=\text { Price per chick (Rs) }
\end{array}
$$

Data on weight gain, FCR, PEF, UP and URI were subjected to analysis of variance (ANOVA) with $\mathrm{P}<0.05$ significant level (SAS, 2000). When significant difference $(\mathrm{P}<0.05)$ were detected, the Duncan Multiple Range Test (DMRT) (Duncan, 1955) was used to compare the mean value. Correlation analyses were performed using SAS (SAS, 2000) to measure the strength of linear association between the FCR, PEF, UP and URI.

\section{RESULTS AND DISCUSSION}

\section{Feed conversion ratio of birds from day 01 to 42}

Feed Conversion Ratio increased with increasing age of birds in both sexes. The male birds should have a lower FCR in general than that of females due to their higher genetic potential for body weight gain. According to Leeson (2000), the FCR in female broilers is usually higher than that in male birds at corresponding weight after about 30 days of age. Leeson (2000) explained that female broilers tend to deposit proportionately more fat in the body than males after about 30 days of age. More energy is used to produce body fat but the contribution to body weight is low. As shown in Table 1, present results show that the male birds had a lower FCR than females at $3^{\text {rd }}$ and $4^{\text {th }}$ week. But the difference was significant only at $3^{\text {rd }}$ week. At the $1^{\text {st }}, 2^{\text {nd }}, 5^{\text {th }}$ and $6^{\text {th }}$ week, females showed a lower FCR than males, though the differences were not significant. 
Table 1. Weekly feed conversion ratio of birds (Mean \pm SE) from day 01 to 42

\begin{tabular}{lcc}
\hline Age (days) & Male $\mathbf{n}=(\mathbf{1 0 8 8}$ or $\mathbf{1 2 7 5} \boldsymbol{?}$ check) & Female $\mathbf{n}=(\mathbf{1 0 8 6}$ or $\mathbf{1 2 7 5} \boldsymbol{~ c h e c k})$ \\
\hline $1-7$ & $1.16 \pm 0.02$ & $1.12 \pm 0.02$ \\
$8-14$ & $1.53 \pm 0.03$ & $1.52 \pm 0.04$ \\
$15-21$ & $1.56 \pm 0.03^{\mathrm{a}}$ & $1.60 \pm 0.05^{\mathrm{b}}$ \\
$22-28$ & $1.77 \pm 0.04$ & $1.79 \pm 0.07$ \\
$29-35$ & $1.81 \pm 0.04$ & $1.80 \pm 0.05$ \\
$36-42$ & $2.14 \pm 0.04$ & $2.10 \pm 0.04$ \\
\hline
\end{tabular}

${ }^{\mathrm{a}, \mathrm{b}}$ Means with different superscripts in a same row are significantly different $(\mathrm{P}<0.05)$.

\section{Feed conversion ratio of birds from day 35 to 42}

There was no significant difference observed in FCR of birds between sexes during day 35 to day 42 (Table 2). However, FCR was affected by the age of the bird independent to the sex. It is well-known fact that the FCR increases as the bird gets old (Lesson, 2000).

Table 2. Feed conversion ratio of male and female broilers (Mean \pm SE) from day 35 to 42

\begin{tabular}{lcc}
\hline Age (days) & Male $\mathbf{n}=(\mathbf{1 0 8 8})$ & Female $\mathbf{n}=\mathbf{( 1 0 8 6 ? )}$ \\
\hline 35 & $1.82 \pm 0.04^{\mathrm{a}}$ & $1.82 \pm 0.05^{\mathrm{a}}$ \\
36 & $1.88 \pm 0.04^{\mathrm{a}}$ & $1.88 \pm 0.05^{\mathrm{a}}$ \\
37 & $1.94 \pm 0.03^{\mathrm{bc}}$ & $1.94 \pm 0.04^{\mathrm{ab}}$ \\
38 & $1.98 \pm 0.01^{\mathrm{cd}}$ & $1.98 \pm 0.04^{\mathrm{bc}}$ \\
39 & $2.03 \pm 0.04^{\mathrm{d}}$ & $2.01 \pm 0.04^{\mathrm{cd}}$ \\
40 & $2.02 \pm 0.03^{\mathrm{d}}$ & $2.03 \pm 0.04^{\mathrm{cd}}$ \\
41 & $2.10 \pm 0.05^{\mathrm{e}}$ & $2.07 \pm 0.05^{\mathrm{de}}$ \\
42 & $2.14 \pm 0.04^{\mathrm{e}}$ & $2.10 \pm 0.04^{\mathrm{e}}$ \\
\hline
\end{tabular}

a, b, c, d, e. Means with different superscripts in a same column are significantly different $(\mathrm{P}<0.05)$.

\section{Performance efficiency factor from day 35 to 42}

As shown in Table 3, female birds always had a lower PEF than males. Except for day 35, values for PEF were significantly different $(\mathrm{P}<0.05)$ between two sexes. Numerically male birds had their highest PEF values at day $36(219.9 \pm 10.0)$ and females had their highest at

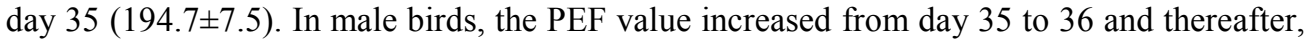
gradually decreased until day 42 , but a significant difference $(\mathrm{P}<0.05)$ was observed only in day 36 to 37 and day 41 to 42 . In female birds, the PEF value decreased from day 35 to 42 , but values were not significantly different. PEF gives a reasonable idea about overall technical efficiency of the broiler operation. The highest PEF value gives the optimum return. Buy-back operators pay incentives for their supervisors based on technical efficiency of the farms which they supervise. For this reason, buy-back operators can use PEF values for their incentive payments and decision making on optimum grow-out period for male and female broilers. 
Table 3. Performance Efficiency Factor of male and female birds (Mean \pm SE) from day 35 to 42

\begin{tabular}{|c|c|c|}
\hline Age (days) & $(n=1088 ?)$ & Female $\quad(n=1086 ?)$ \\
\hline 35 & $214.4 \pm 8.9^{\mathrm{a}}$ & $194.7 \pm 7.5^{\mathrm{a}}$ \\
\hline 36 & $219.9 \pm 10.0^{\mathrm{ax}}$ & $193.0 \pm 8.0^{\mathrm{ay}}$ \\
\hline 37 & $208.3 \pm 7.8^{b x}$ & $186.5 \pm 7.4^{\text {aby }}$ \\
\hline 38 & $207.7 \pm 9.1^{\mathrm{bx}}$ & $182.8 \pm 7.0^{\text {abcy }}$ \\
\hline 39 & $202.6 \pm 9.3^{b x}$ & $178.6 \pm 6.2^{\text {bcdy }}$ \\
\hline 40 & $204.6 \pm 7.9^{\mathrm{bx}}$ & $179.4 \pm 6.6^{\text {bcdy }}$ \\
\hline 41 & $195.6 \pm 8.9^{\mathrm{bcx}}$ & $175.2 \pm 6.6^{\mathrm{cdy}}$ \\
\hline 42 & $186.6 \pm 7.5^{\mathrm{cx}}$ & $171.3 \pm 5.98^{\mathrm{dy}}$ \\
\hline
\end{tabular}

${ }^{\mathrm{x}, \mathrm{y}}$ : Means with different superscripts in a same row are significantly different $(\mathrm{p}<0.05)$.

$\mathrm{a}, \mathrm{b}, \mathrm{c}, \mathrm{d}$, : Means with different superscripts in a same column are significantly different $(\mathrm{p}<0.05)$.

\section{Unit profitability from day 35 to 42}

Males had a significantly higher $(\mathrm{P}<0.05)$ UP than females from day 35 to day 42 (Table 4 ). For males, UP had increased from day 35 up to day 40 and reduced thereafter. Males achieved the highest value of UP (61.7 \pm 1.9$)$ at day 40 but were not significantly different from day 39. Value of UP had decreased from day 40 to 42 in males but were not significantly different. In female birds, UP value had increased from day 35 to 42 and showed the highest value of UP, $52.0 \pm 1.3$ at day 42 . The increasing weights of the birds increase the UP till it comes to the maximum stocking density of the house. In this trial, as practiced in Sri Lankan poultry farms, the same floor space per bird were provided for both sexes. In general, the males have more flesh than the females at the same age. Therefore, the males must have come to the maximum stocking density at day 40 and females didn't come to the maximum even at day 42 . The same reason has been affected to have significantly higher $(\mathrm{P}<0.05)$ UP values in males than in females during day 35 to day 42 . When the capacity is limited, and the time is at premium, UP can be used to asses the profitability of the broiler operation. Housing cost and environment control cost per unit area is very high in closed-house operations and compartmentalized operations compared to open sided houses. Therefore, closed-house operators and compartmentalized operators (caged system) can use the day which gives the highest UP value as the optimum grow out period.

Table 4. Unit Profitability (Rs $\left./ \mathrm{m}^{2} / \mathrm{day}\right)$ of male and female broilers (Mean $\pm \mathrm{SE}$ ) from day 35 to 42

\begin{tabular}{|c|c|c|}
\hline Age (days) & Male $n=(1088 ?)$ & Female $n=(1086 ?)$ \\
\hline 35 & $54.8 \pm 1.9^{\mathrm{ax}}$ & $46.3 \pm 1.3^{\mathrm{ay}}$ \\
\hline 36 & $57.2 \pm 2.1^{\mathrm{bcx}}$ & $47.5 \pm 1.5^{\text {by }}$ \\
\hline 37 & $57.2 \pm 1.7^{\mathrm{bx}}$ & $47.9 \pm 1.4^{\text {by }}$ \\
\hline 38 & $58.9 \pm 2.1^{\mathrm{bcdx}}$ & $48.8 \pm 1.4^{\text {bcy }}$ \\
\hline 39 & $59.6 \pm 2.1^{\mathrm{bcdx}}$ & $49.5 \pm 1.2^{\mathrm{bcdy}}$ \\
\hline 40 & $61.7 \pm 1.9^{\mathrm{dx}}$ & $51.1 \pm 1.4^{\text {cdey }}$ \\
\hline 41 & $61.0 \pm 2.2^{\mathrm{cdx}}$ & $51.5 \pm 1.3^{\mathrm{dey}}$ \\
\hline 42 & $60.1 \pm 2.0^{\mathrm{cdx}}$ & $52.0 \pm 1.3^{\mathrm{ey}}$ \\
\hline
\end{tabular}

${ }^{\mathrm{x}, \mathrm{y}}$ : Means with different superscripts in a same row are significantly different $(\mathrm{P}<0.05)$.

$\mathrm{a}, \mathrm{b}, \mathrm{c}, \mathrm{d}, \mathrm{e}$ : Means with different superscripts in a same column are significantly different $(\mathrm{P}<0.05)$. 


\section{Unit return index from day 35 to 42}

The unit return index in males were significantly higher $(\mathrm{P}<0.05)$ than that in females at a given age (Table 5). Both sexes showed a significantly higher $(\mathrm{P}<0.05)$ increase from day 35 to day 36. Males reached the highest URI value at day $40(6123 \pm 444)$ and reduced thereafter. But values were not significantly different from day 39 to day 42 . Females reached the highest value at day 42 (4612 \pm 282$)$. But values were not significantly different from day 40 to day 42.

Table 5. Unit return index of male and female broilers (Mean \pm SE) from day 35 to 42

\begin{tabular}{|c|c|c|}
\hline Age (days) & $(n=1088 ?)$ & $(n=1086 ?)$ \\
\hline 35 & $4956 \pm 361^{\mathrm{ax}}$ & $3879 \pm 236^{\text {ay }}$ \\
\hline 36 & $5424 \pm 427^{\mathrm{bcx}}$ & $4052 \pm 253^{\text {by }}$ \\
\hline 37 & $5383 \pm 375^{\mathrm{bx}}$ & $4110 \pm 243^{\text {by }}$ \\
\hline 38 & $5666 \pm 426^{\mathrm{bcdx}}$ & $4252 \pm 259^{\text {bcy }}$ \\
\hline 39 & $5815 \pm 456^{\text {cdex }}$ & $4297 \pm 228^{\text {bcy }}$ \\
\hline 40 & $6123 \pm 444^{\mathrm{ex}}$ & $4498 \pm 261^{\mathrm{cdy}}$ \\
\hline 41 & $6050 \pm 479^{\operatorname{dex}}$ & $4510 \pm 249^{\text {cdy }}$ \\
\hline 42 & $5929 \pm 485^{\text {cdex }}$ & $4612 \pm 282^{\text {dy }}$ \\
\hline
\end{tabular}

${ }^{\mathrm{x}, \mathrm{y}}$ : Means with different superscripts in a same raw are significantly different $(\mathrm{P}<0.05)$.

a, b, c, d, e: Means with different superscripts in a same column are significantly different $(\mathrm{P}<0.05)$.

The stocking rate of bird was used for the calculation of these values. As in the UP, the values in females were always lower than those of males at a given age because both males and females were given the same floor space per bird. URI gives an idea about overall technical efficiency of the broiler operation as well as maximize the utilization of floor area of the house. Therefore, URI can be recommended for buy-back operators, closed-house operators and compartmentalized operators to make decision on optimum grow-out period and incentive payments.

\section{Correlation between different indices}

Some of the parameters like body weight gain, feed intake, age, livability and stocking rate were common to all indices. Therefore, mathematical correlations between some indices were exist (Table 6). According to the correlation analysis, FCR had a negative correlation with PEF, UP and URI in both male and female birds. Out of these correlations, the correlation between FCR and PEF was the greatest. Therefore, the best slaughtering age in both male and female is the day where the highest PEF as well as lowest FCR is achieved. A positive correlations were observed between PEF and UP, PEF and URI and UP and URI in both sexes while males showed high values compared to females. In males, UP and URI showed the highest correlation as both indices reached the highest at day 40. 
Samarakoon and Samarasinghe

Table 6. Correlation between different indices for male and female birds $(\mathrm{P}<0.05)$

\begin{tabular}{lcc}
\hline \multirow{2}{*}{ Indices } & \multicolumn{2}{c}{ Correlation coefficient } \\
\cline { 2 - 3 } & Male & Female \\
\hline FCR \& PEF & -0.8327 & -0.8896 \\
FCR \& UP & -0.6336 & -0.6311 \\
FCR \&URI & -0.4046 & -0.4279 \\
PEF \& UP & 0.9102 & 0.8406 \\
PEF \&URI & 0.8218 & 0.7646 \\
UP \&URI & 0.9190 & 0.8796 \\
\hline
\end{tabular}

\section{CONCLUSIONS}

FCR increased with increasing age in both sexes from day 1 to day 42 . But there was no consistency in FCR with respect to age or sex of the birds during day 35 to day 42 . Therefore FCR cannot be considered as a good index to make a decision on optimum grow-out period. Depending on the PEF values, males should be slaughtered at day 36 to get the optimum return. Depending on the UP and URI values day 40 can be considered as the optimum growout time for male broilers. Further researches are needed to find out the optimum grow-out period of females based on PEF, UP and URI. Sex-separate growing can be recommended to broiler operations as male and female broilers had different optimum grow-out periods when assessing the performance with the same parameter.

\section{ACKNOWLEDGEMENTS}

Authors gratefully acknowledge research facility given by the CIC Feeds (Pvt.) Ltd., Ekala, Sri Lanka and grateful to Mr. Lal Silva, Managing Director of the company for the financial support provided.

\section{REFERENCES}

Creswell, D. (2007). Feeding the broiler. Asian Poultry Magazine, July 2007, 20-23.

Creswell, D. (2005). The nutritional requirements of today's broiler. Asian Poultry Magazin May 2005, 18-21.

Duncan, D.B. (1955). Multiple range and multiple F-Test. Biometrics. 11, 1-42.

Gunasekar, K.R. (2007). Formulating feeds for broiler performance.

[on line]. [Accessed on 02.03.2009]. Available at

http://www.thepoultrysite.com/articles/560/formulating-feed-for-broilerperformance.

Kleyn, R. (2002). Strategies for managing expensive feed on farm. [on line]. [Accessed on 08.03.2009]. Available at www.spesfeed.co.za/Strategies_for_managing_Expensive_Feed_on_Farm. 
Leeson. (2000). Is feed efficiency still a useful measure of broiler performance. [on line]. [Accessed on 10.03.2009]. Available at http://www.omafra.gov.on.ca/english/livestock/poultry/facts/efficiency.htm

SAS Institute. (2000). SAS/STAT User's guide. Version 9.5, SAS Institute, Cray, NorthCarolina, USA

Veerapen, D.D. (1999). Separate sex growing of Ross 208 broilers and effect on broiler performance and carcass quality.[on line]. [Accessed on 08.03.2009]. Available at www.uom.ac.mu/provcrci/researchjournal/.../pdf pg\%20145-159.pdf

Waller, A. (2007). Take a fresh look at broiler nutrition. Poultry International, September 2007, 12-13. 